\title{
Study on the effect of fractures on conventional induction log based on physical and numerical simulation
}

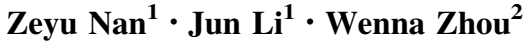

Received: 27 July 2015/Accepted: 16 February 2016/Published online: 25 February 2016

(C) Akadémiai Kiadó 2016

\begin{abstract}
Fractures are important storage area and migration pathway in fractured reservoir. Abnormal conventional induction logging response has been found in fracture zone of reservoir, but few scholars have studied the conventional induction log response of fractured reservoirs. In this paper, the effect of fractures on conventional induction log has been studied based on physical and numerical simulation. Firstly, a physical model has been built to simulate the influence of fractures on conventional log. Secondly, the geometric factor theory has been used to find the minimum fracture width that the conventional induction log could identify, and the minimum interval between two adjacent fractures that the conventional induction log could distinguish. Thirdly, a fracture evaluation method based on numerical simulation was proposed, and a complex model containing surrounding rock and fractures was established to test the possibility of evaluating the fracture parameters using this method. Finally field data were used to test this method. From the results in this paper, we conclude that fractures influence conventional induction log significantly and fractures could be detected and evaluated by the conventional induction log.
\end{abstract}

Keywords Conventional induction $\log$ - Fracture evaluation · Physical simulation · Numerical simulation

\section{Introduction}

Fractures are important storage area and migration pathway in fractured reservoir such as carbonate reservoir, tight sand reservoir and shale reservoir. Resistivity logging is an important way to evaluate fracture parameters. Much knowledge has been acquired in past

Zeyu Nan

nanzy.syky@sinopec.com

1 Exploration \& Production Research Institute, SINOPEC, Beijing 100083, China

2 School of Earth Sciences, Key Laboratory of Mineral Resources in Western China

(Gansu Province), Lanzhou University, Lanzhou 730000, Gansu, China 
years on how unconventional resistivity logging equipment such as resistivity imaging logging, azimuth laterolog and multicomponent induction logging response to fractures (Chester and Gregory 2002; Rabinovich et al. 2004; Zhang et al. 2004; Wang et al. 2005; Xue et al. 2008; Wu et al. 2013). However, in some oil field unconventional logging data are lacking because the cost of these logs is much higher than that of the conventional resistivity logs such as laterolog and induction log. Furthermore, the later application of unconventional $\log$ will lead to the lack of these unconventional logging data in wells drilled earlier.

Conventional resistivity logging equipment include laterolog and induction log, which could be used for detecting fractures due to the different resistivity between fractures filled with drilling fluids or formation water and surrounding rocks. Sibbit and Faivre (1985) has proposed fracture parameter evaluation model suitable for laterolog, and this model has been widely accepted. In spite of that, occasionally abnormal conventional induction logging response has been found in fracture zone of reservoir, and few scholars have studied the conventional induction log response of fractured reservoirs.

A physical model has been built to simulate the influence of fractures on conventional log ( $0.8 \mathrm{~m}$ six coil system induction $\log$ and 1503 dual induction $\log$ ) in this paper. The geometric factor theory, which is recognized as the most effective one for near zone field, has been used to find the minimum fracture width that the conventional induction log could identify, and the minimum interval between two adjacent fractures that the conventional induction log could distinguish. Physical simulation results and numerical simulation results have been compared to make sure we get correct results. Then a fracture evaluation method based on numerical simulation was proposed, and a complex model containing surrounding rock and fractures was established to test the possibility of evaluating the fracture width using this method. Finally field data were used to test this method. From the results in this paper, we conclude that fractures influence conventional induction log significantly and fractures could be detected and evaluated by the conventional induction log.

\section{Physical simulation of conventional induction log response to fractured formation}

In order to simulate the influence of fractures on conventional log, a physical model containing fracture, surrounding rock and conventional induction logging equipment ( $0.8 \mathrm{~m}$ six coil system induction $\log$ and 1503 dual induction $\log$ ) was built. Conductive rings were used to simulate surrounding rock, and conductive meshes were used to simulate fractures in formation in this model. Figure 1 shows measurement results of this model. The resistivities of surrounding rock and fracture are 50 and $0.05 \mathrm{ohm} \mathrm{m}$, respectively, and the fracture width is $5.45 \mathrm{~mm}, \mathrm{z}$ is the location of the equipment.

Form Fig. 1 we can determine that fracture in the formation has influence on conventional induction log and apparent conductivity will increase significantly in fracture zone, hence conventional induction log could be used to evaluate fracture parameter. In order to find out the relationship between fracture and log response, numerical simulation has been introduced in this paper.

\section{Geometric factor theory of conventional induction log}

The geometric factor theory is the most effective theory for near zone field. Doll (1949) proposed the Doll geometric factor to explain the basic theory of induction log when induction logging method was proposed. Doll geometric factor could be used to illustrate 
(a)

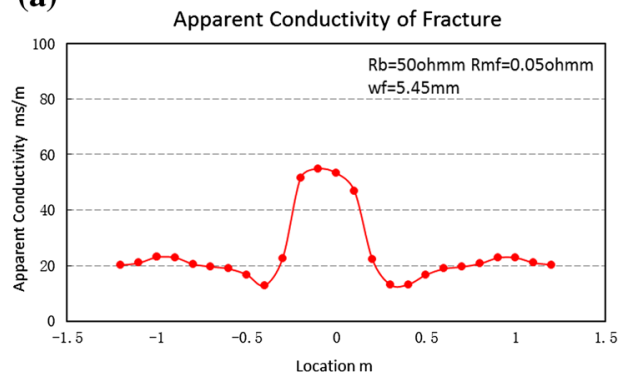

(b)

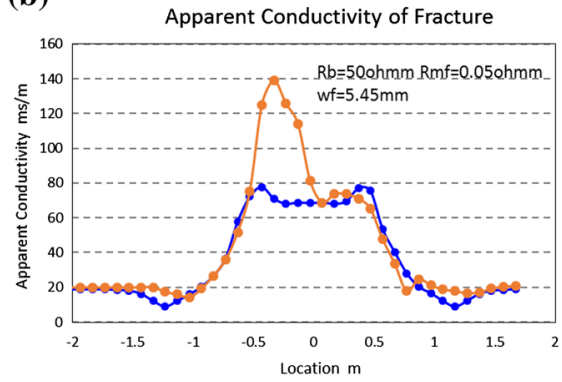

Fig. 1 a $0.8 \mathrm{~m}$ six coil system induction $\log$ response of simulated fracture. b 1503 dual induction log response of simulated fracture

the contribution of borehole reservoir and surrounding rocks to induction logging signal. The formation is divided into conductive rings, and the interaction between these conductive rings is ignored according to the Doll geometric factor theory. The Doll geometric factor of double loop induction log is shown in formula (1).

$$
g_{\text {doll }}(r, z)=\frac{L}{2} \frac{r^{3}}{r_{R}^{3} r_{T}^{3}} .
$$

In the formula above, $\mathrm{L}$ is the distance between the transmit coil and the receive coil, $\mathrm{r}_{\mathrm{R}}$ is the distance between receive coil and conductive rings which represent formation, $\mathrm{r}_{\mathrm{T}}$ is the distance between transmit coil and conductive rings, and $\mathrm{r}, \mathrm{z}$ are the coordinates.

Doll geometric factor cannot be used in high conductivity formation, due to the seriously skin effect which will lead to the attenuation of electromagnetic energy. Gianzero and Anderson (1981) proposed the Gianzero geometric factor which takes the skin effect into consideration. The Gianzero geometric factor of double loop induction log is shown in formula (2).

$$
g_{\text {Gian }}=\frac{1}{2} g_{\text {Doll }\left\{\left(1-i k r_{T}\right) e^{i k r T}+\left(1-i k r^{R}\right) e^{i k r_{R}}\right\}} .
$$

In the formula above, $\mathrm{g}_{\text {Doll }}$ is the Doll geometric factor, $k=\sqrt{ }(-i \omega \mu \sigma)$ is the wave number of the electromagnetic wave, $r_{R}$ is the distance between receive coil and conductive rings which represent formation, $\mathrm{r}_{\mathrm{T}}$ is the distance between transmit coil and conductive rings. This geometric factor takes eddy current in conductive rings into consideration (Anderson et al. 1998). In this paper, the Gianzero geometric factor is chosen to simulate the induction log single of fractured formation.

\section{Numerical simulation of conventional induction log response to fractured formation}

Two kinds of fractured reservoir models with various fracture parameters have been built to test the capability of conventional induction log to detect and evaluate fractures in this simulation. One is the single fracture model with various fracture conductivities to test the capability of conventional induction log to identify single fracture in reservoir. The other is the dual fracture model with different fracture intervals to test the capability of 
conventional induction log to distinguish adjacent fractures. Figure $2 \mathrm{a}$ illustrates the single fracture model, and Fig. $2 b$ illustrates the dual fracture model. In these figures $w_{f}$ is fracture width, $d_{f}$ is the distance between adjacent fractures, $d_{i}$ is borehole diameter, $d_{e}$ is the diameter of logging equipment, $R_{s}$ is surrounding rock resistivity, $R_{f}$ is fracture resistivity and $R_{m}$ is mud resistivity.

$0.8 \mathrm{~m}$ six coil system induction log, and 1503 dual induction log made by Baker Atlas are two kinds of conventional induction logging equipments widely used in oil base mud. The responses of these two kinds of logging equipments were simulated according to the Gianzero geometric factor theory. In the simulation of the single fracture model, fracture width $\mathrm{w}_{f}$ is a variable with values of $10,1 \mathrm{~mm}, 100$ and $10 \mu \mathrm{m}$. In the simulation of the dual fracture model adjacent fracture interval $\mathrm{d}_{f}$ is an variable with values of 5, 2, 1.5 and $1 \mathrm{~m}$. Other parameters are stable in these two kinds of models. $\mathrm{R}_{s}$ (resistivity of surrounding rock) is $50 \mathrm{ohm} \mathrm{m}, \mathrm{R}_{f}$ (resistivity of surrounding fracture) is $0.05 \mathrm{ohm} \mathrm{m}, \mathrm{R}_{m}$ (resistivity of surrounding mud) is $1 \mathrm{ohm} \mathrm{m}$, and $\mathrm{d}_{\mathrm{i}}$ (diameter of borehole) is $8.5 \mathrm{in}$. During the simulation, borehole correction was took into consideration. The simulation results of $0.8 \mathrm{~m}$ six coil system induction $\log$ and 1503 dual induction $\log$ of the single fracture model are demonstrate in Figs. 3 and 4. The simulation results of $0.8 \mathrm{~m}$ six coil system induction $\log$ and 1503 dual induction log of the dual fractures model are demonstrate in Figs. 5 and 6.

From these figures we can easily find that fracture has a significant effect on conventional $\log$ response, and there is a positive correlation between amplitude and fracture conductibility. From Figs. 3 and 4 we conclude that fractures wider than $100 \mu \mathrm{m}$ can be identified by the conventional induction log, and fractures narrower than $100 \mu \mathrm{m}$ might be ignored. Figure 5 shows that when the distance between two adjacent fractures is larger than $1.5,0.8 \mathrm{~m}$ six coil system induction $\log$ can distinguish two fractures from each other in the dual fracture model. In contrast, when the distance is smaller than $1 \mathrm{~m}$, the responses of these two fractures merge into one. Figure 6 suggests that even when the distance between these two fractures is $1 \mathrm{~m}$, they can still be distinguished by the 1503 dual induction $\log$.

In order to reveal the minimum interval between two adjacent fractures that conventional induction log could identify, more numerical simulation models with various fracture intervals were built. As shown in Fig. 7, the minimum intervals for $0.8 \mathrm{~m}$ six coil system induction log and 1503 dual induction log are 1.3 and $0.9 \mathrm{~m}$, respectively.

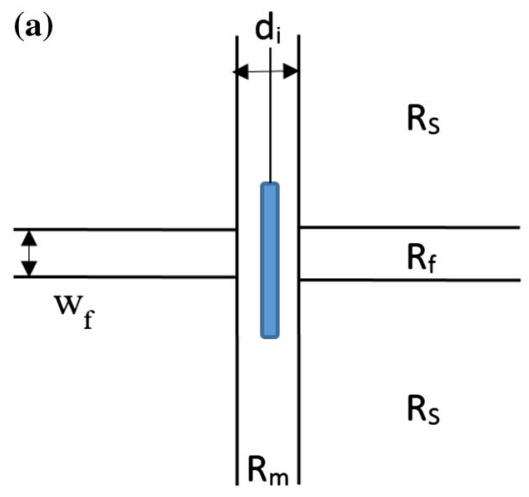

(b)

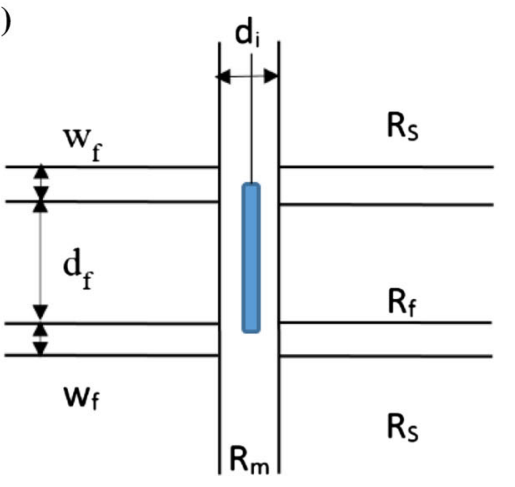

Fig. 2 a The single fracture model of conventional induction log. b The Dual fractures model of conventional induction $\log$ 


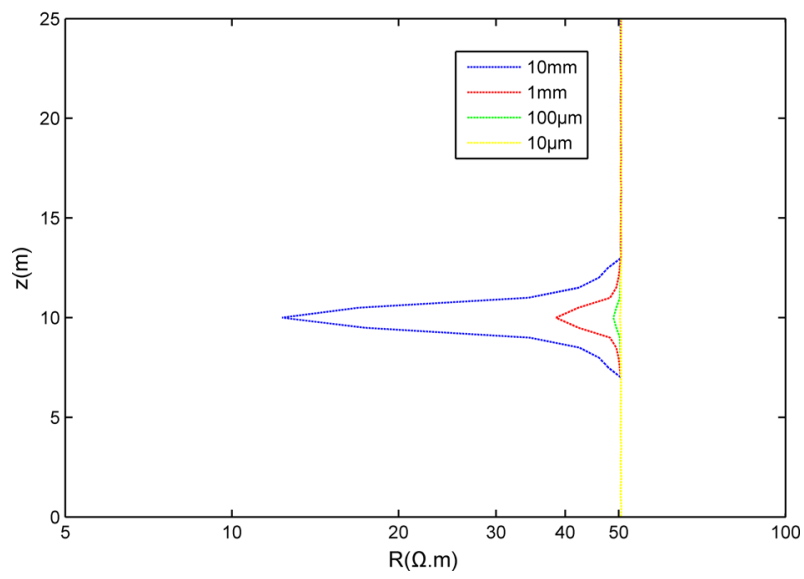

Fig. 3 The $0.8 \mathrm{~m}$ six coil system induction log response of different fracture width

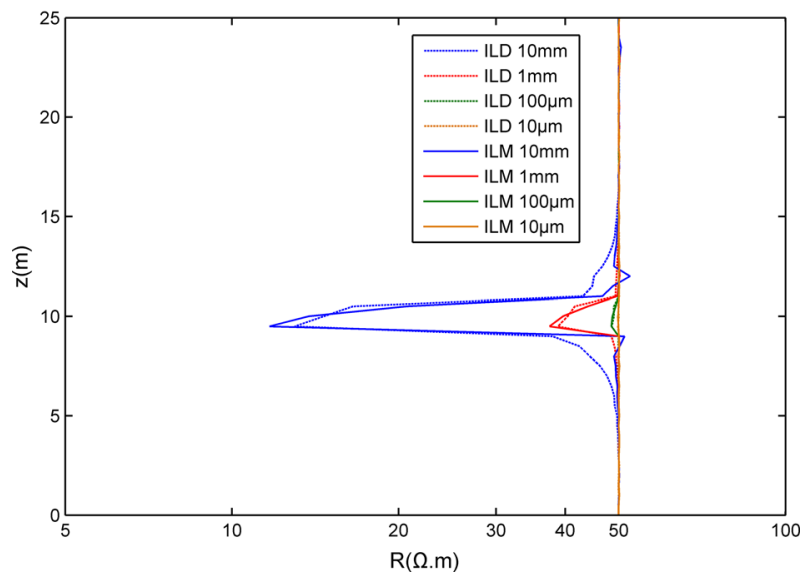

Fig. 4 The 1503 dual induction log response of different fracture width

\section{Mutual authentication of numerical simulation and physical simulation}

In order to make sure we get correct results, the results of the physical simulation and numerical simulation were compared and analysed.

In this part, four conductive meshes with different surface conductivities $(0.88,9.2,18.4$ and $90.2 \Omega$ ) were made to simulate fractures saturated formation water with a resistivity of $0.05 \mathrm{ohm} \mathrm{m}$ and different widths $(74.2,5.45,2.7 \mathrm{~mm}$ and $550 \mu \mathrm{m})$. First the induction $\log$ responses of these four meshes were measured. Then the logging responses of various fracture widths were calculated by numerical simulation based on the Gianzero geometric factor, which was mentioned in the previous section. Finally, experimental results and numerical simulation results are compared in Figs. 8 and 9.

Figure 8 shows the experimental results and numerical simulation results of $5.45 \mathrm{~mm}$ fracture. The solid line is the numerical simulation logging response of the 1503 dual 

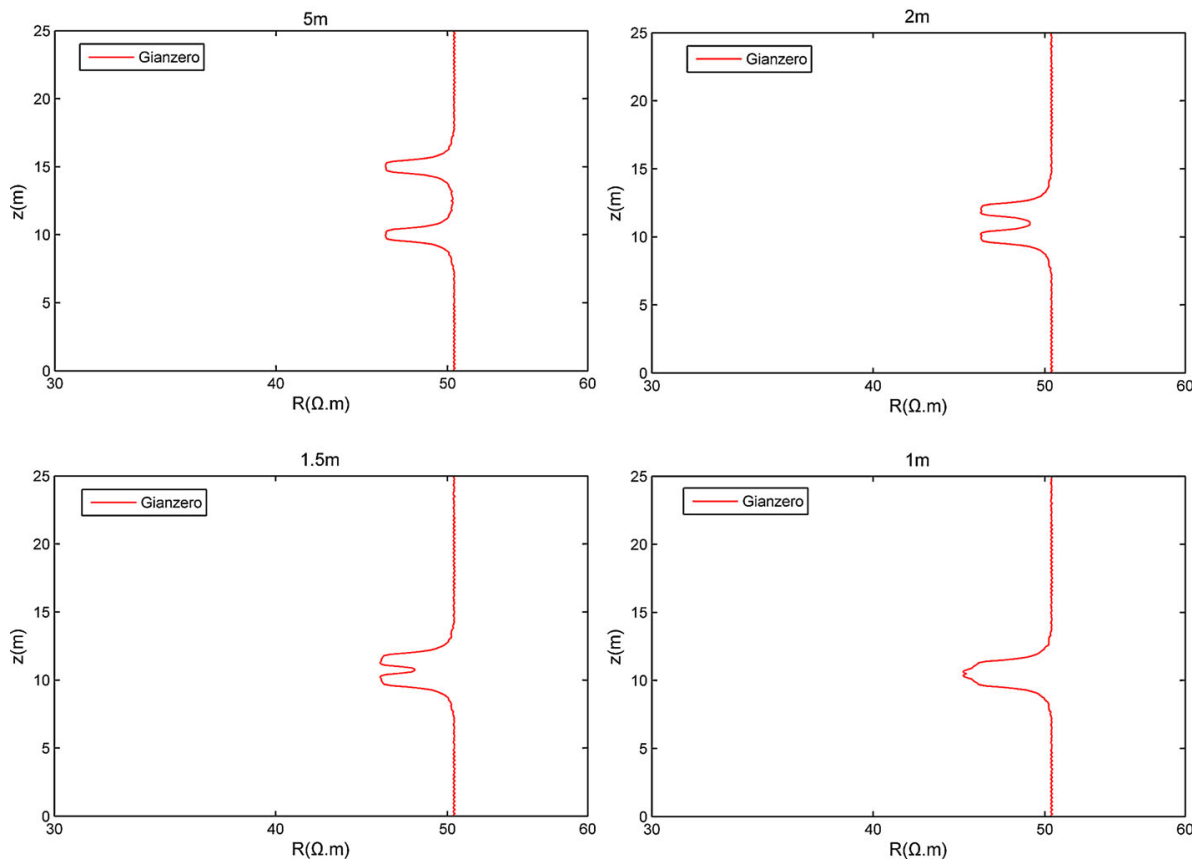

Fig. $50.8 \mathrm{~m}$ six coil system induction log response of different fracture intervals

induction log, and the point line is the experimental results of this equipment. From this figure we conclude that the amplitude and shape of physical and numerical simulation are nearly the same. Figure 9 shows the comparison between numerical simulation results of various fracture widths and physical simulation results of these four meshes. In Fig. 9 the solid line is the 1503 dual induction log response at the recoding point, and the point line is the experimental result. As can be seen from this figure, physical simulation and numerical simulation are nearly the same, and the physical and numerical simulation methods used in this paper are correct.

\section{Fracture parameter evaluation method using the conventional induction log based on numerical simulation}

According to the numerical simulation based on the geometric factor theory in the previous part of this paper, we can build a fracture parameter evaluation method to calculate fracture or fracture zone parameters. In this model fracture depth is located by the position of the extreme point. An initial fracture with fracture width h0 was assumed at the extreme point. Then the exact fracture width was calculated by the damping least square method. Finally, a complex model contain surrounding rock and fractures were used to test the capability of this conventional induction log fracture evaluation method.

The complex model contains surrounding rocks with various resistivities and three fractures at the depth of 15,45 and $47 \mathrm{~m}$. The fracture width is $100 \mu \mathrm{m}$. The resistivity of 

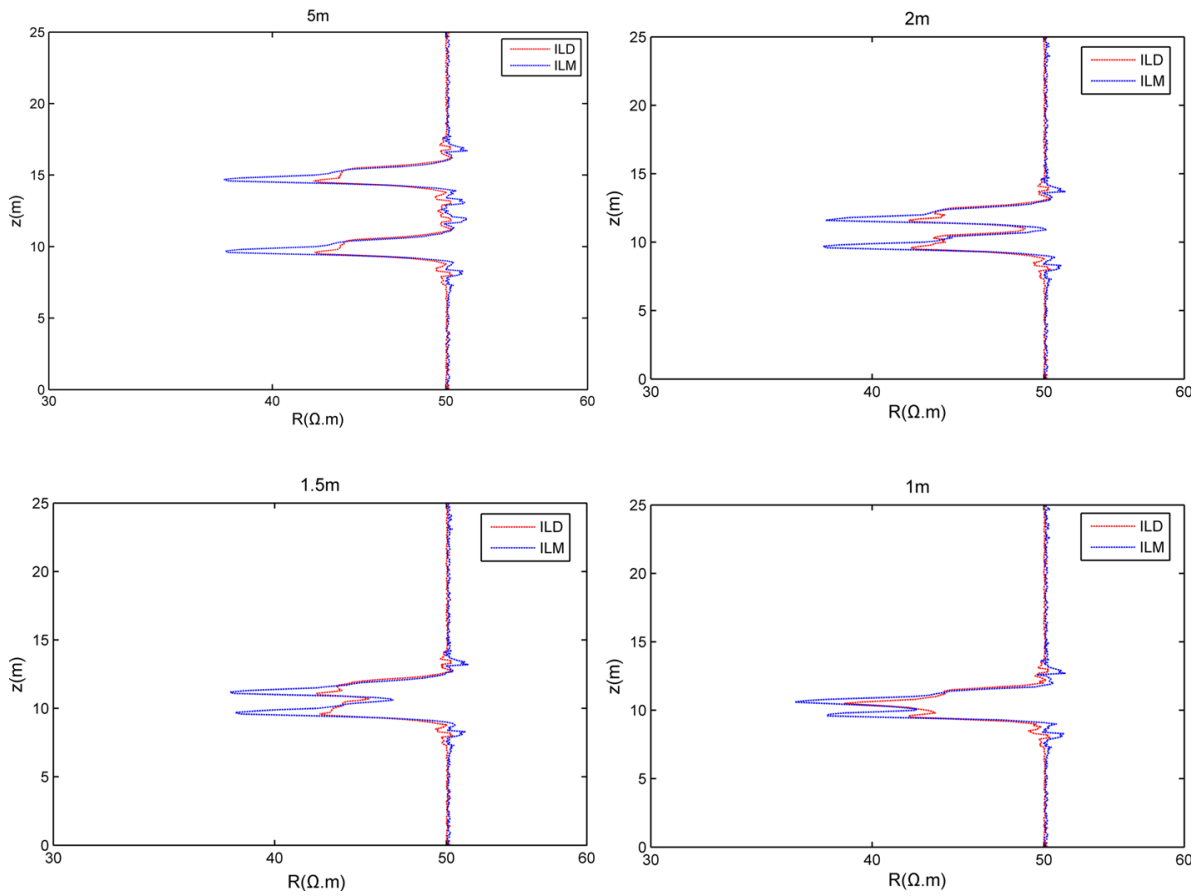

Fig. 61503 dual induction log response of different fracture intervals

(a)

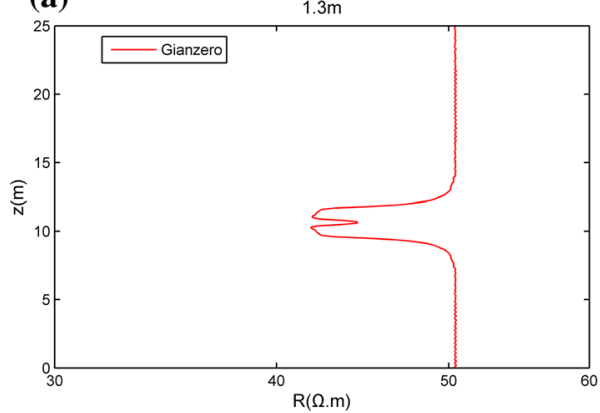

(b)

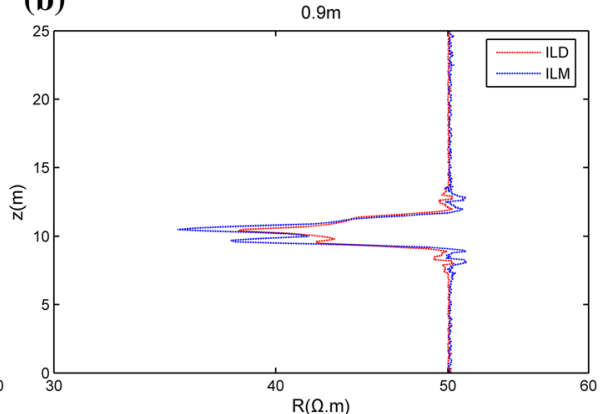

Fig. 7 a The $0.8 \mathrm{~m}$ six coil system induction log response of minimum fracture interval. b The 1503 dual induction $\log$ response of minimum fracture interval

this model is shown in Fig. 10a. The inversion result is shown in Table 1 and Fig. 10b shows the logging response (blue line) and the inversion result curve of this model.

In order to test if this method can be used to evaluate fracture parameter, field data of Well A was used (Fig. 11). Well A is a productive well in H oilfield southwest China, and we can see two fracture zones in this well at the depth of 3175.5 and $3190 \mathrm{~m}$ from FMI dynamic image, the porosities of which are 0.16 and $0.13 \%$. The fracture depth and porosity inversed from induction log using this inversion method are shown in Fig. 11 in 


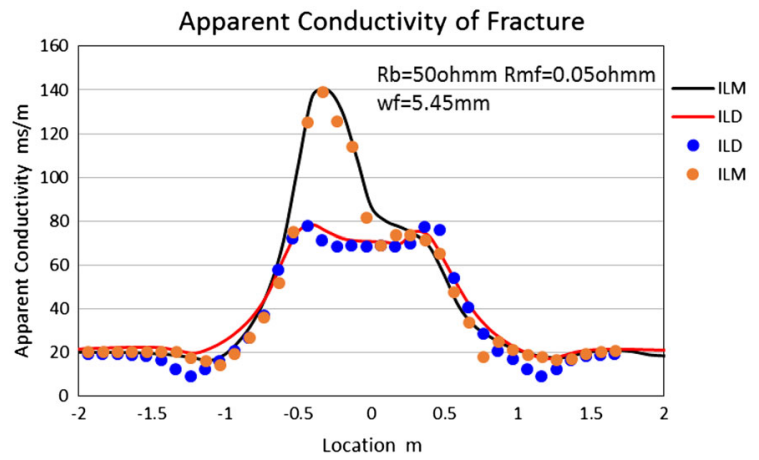

Fig. 8 Physical and numerical simulation results of the 1503 dual induction logging response to $5.45 \mathrm{~mm}$ fracture

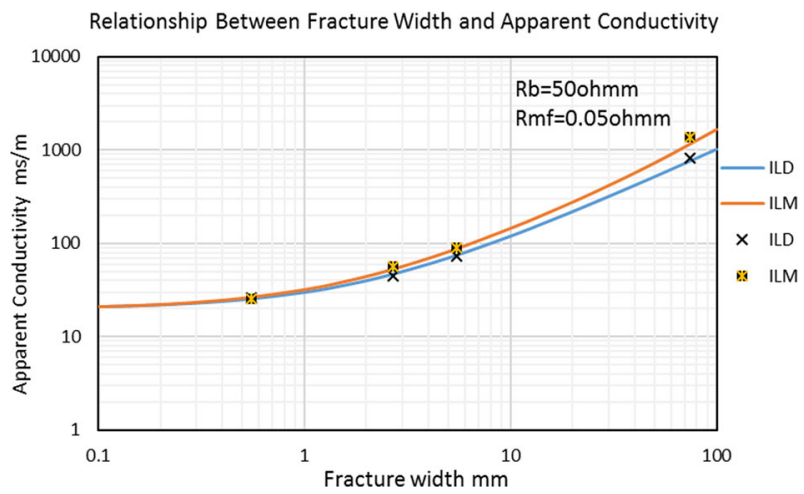

Fig. 9 Physical and numerical simulation results of the 1503 dual induction logging response at recording points of various fracture width

(a)

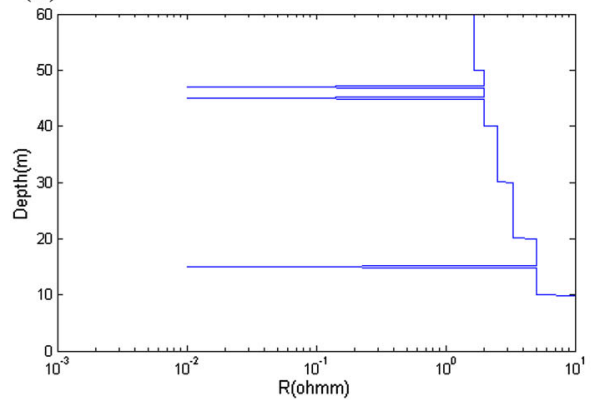

(b)

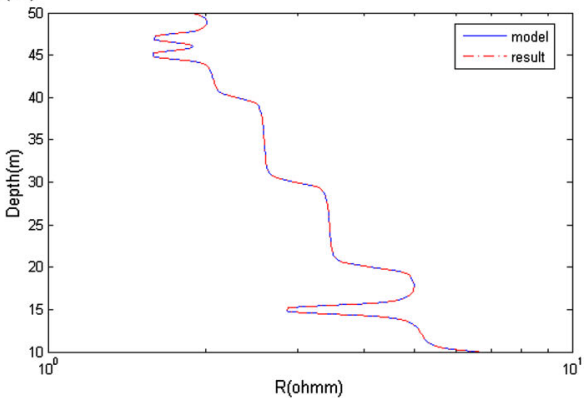

Fig. 10 a The resistivity of the complex model. b The forward and inverse logging response of this complex model 
Table 1 Inversed fracture width and fracture of complex model

\begin{tabular}{llllllll}
\hline Iteration times & Fitting error & \multicolumn{2}{l}{ Fracture width and } \\
& & \multicolumn{2}{l}{$\begin{array}{l}\text { Fracture width and } \\
\text { depth at } 45 \mathrm{~m}\end{array}$} & \multicolumn{3}{l}{$\begin{array}{l}\text { Fracture width and } \\
\text { depth at } 47 \mathrm{~m}\end{array}$} \\
\hline 1 & 4.093010 & 0.000010 & 15 & 0.000007 & 45 & 0.000009 & 47 \\
2 & 1.137840 & 0.006537 & 15 & 0.005657 & 45 & 0.005523 & 47 \\
3 & 0.185146 & 0.009560 & 15 & 0.008609 & 45 & 0.008403 & 47 \\
4 & 0.028191 & 0.009987 & 15 & 0.009713 & 45 & 0.009477 & 47 \\
5 & 0.003956 & 0.010000 & 15 & 0.009960 & 45 & 0.009716 & 47 \\
6 & 0.002579 & 0.010000 & 15 & 0.009989 & 45 & 0.009742 & 47 \\
7 & 0.002573 & 0.010000 & 15 & 0.009991 & 45 & 0.009744 & 47 \\
\hline
\end{tabular}

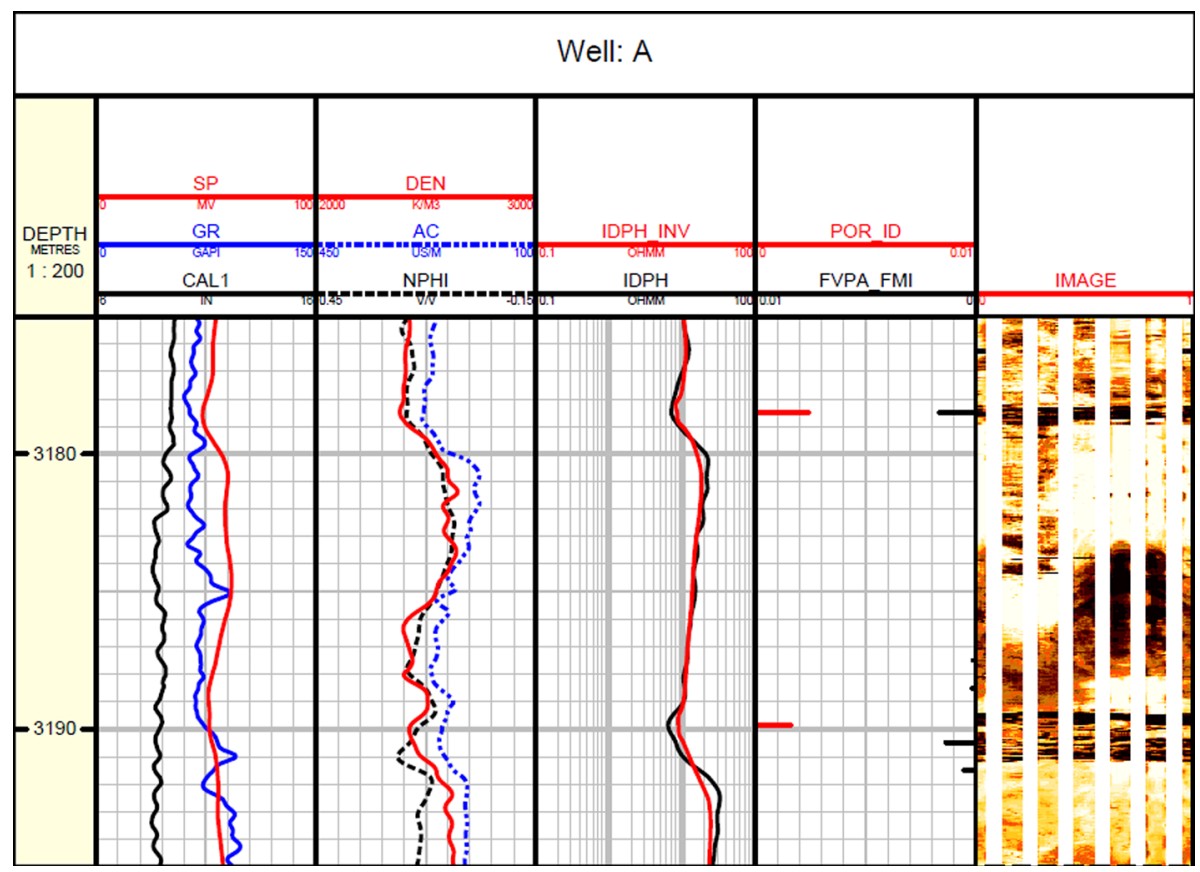

Fig. 11 Comprehensive processing result in well A

red lines. From this figure we can see the inversed fracture depth and porosity are consistent with the fracture parameter from FMI, and this inversion method could be used for fracture evaluation using the conventional induction log.

\section{Conclusions}

Physical and numerical fractured reservoir models have been built in this article to study the effect of fractures on conventional induction log. Then the numerical simulation were verified via experimental results. Furthermore, according to the numerical simulation result 
a fracture parameter inversion model based on damping least square method was proposed. Finally this inversion model was used to evaluate fracture parameters from complex model and real data. From the simulation we conclude that

(1) The Gianzero geometric factor method could be used to calculate the induction log response, and the logging response calculated by this method matches the experimental data measured by actual instrument.

(2) Fractures in reservoir influence the conventional induction log response significantly, and there is a positive correlation between amplitude difference of logging response and fracture conductibility according to physical and numerical simulation. The amplitude difference of logging response can be used to evaluate fracture parameters.

(3) Single fracture wider than $100 \mu \mathrm{m}$ could be identified from the conventional log, and fractures smaller than this level might be ignored. The conventional induction $\log$ can distinguish adjacent fractures, and the minimum fracture intervals for the 0.8 $\mathrm{m}$ six coil system induction $\log$ and the 1503 dual induction $\log$ are 1.3 and $0.9 \mathrm{~m}$ under the previously mentioned model conditions.

(4) According to the simulation result of induction log, fracture depth and porosity can be determined by inversion method from the conventional induction log.

Acknowledgments This work is supported by Sinopec Scientific and Technological Project (P13111) (P14136) and Chinese National Science and Technology Major Project 2011ZX05005-006-006.

\section{References}

Anderson BI, Barber TD, Gianzero SC (1998) The effect of crossbedding anisotropy on induction tool response. In: SPWLA 39th annual logging symposium, 26-29 May

Chester JW, Gregory AN (2002) Electromagnetic induction in a fully 3-D anisotropic earth. Geophysics 67:1104-1114

Doll HG (1949) Introduction to induction logging and application to logging of wells drilled with oil base mud. J Petrol Technol 1(6):148-162

Gianzero S, Anderson B (1981) A new look at skin effect. In: SPWLA 22th annual logging symposium, 23-26 June

Rabinovich M, Bespalov A, Corley B, Merchant G, Wang T, Quint E, Morrison J (2004) Effect of fractures on multi-component and multiarray induction logs. In: SPWLA 45th annual logging symposium, 6-9 June

Sibbit AM, Faivre Q (1985) The dual laterolog response in fractured rocks. In: SPWLA. 26th annual logging symposium, 17-20 June

Wang T, Tang XM, Yu LM, Kriegsh B, Fanini O, Ugueto G (2005) Characterizing fractures with multicomponent induction measurements. Petrophysics 46(1):42-51

Wu P, Barber T, Wang GL, Johnson C, Heliot D, Hayden R, Kumar A, Wang H, Clinch S, Schmidt CL (2013) Fracture characterization using triaxial induction tools. In: SPWLA 54th annual logging symposium, 22-26 June

Xue D, Rabinovich M, Bespalov F, Corley B (2008) Characterization of fracture length and formation resistivity from array induction data. In: SPWLA 49th annual logging symposium, 25-28 May

Zhang ZY, Yu LM, Berthold K, Lev T (2004) Determination of relative angles and anisotropic resistivity using multicomponent induction logging data. Geophysics 69(4):898-902 